\title{
The relation between depressive and obsessive- compulsive symptoms in obsessive-compulsive disorder: Results from a large, naturalistic follow-up study
}

Citation for published version (APA):

Rickelt, J., Viechtbauer, W., Lieverse, R., Overbeek, T., van Balkom, A. J., van Oppen, P., van den Heuvel, O. A., Marcelis, M., Eikelenboom, M., Tibi, L., \& Schruers, K. R. J. (2016). The relation between depressive and obsessive-compulsive symptoms in obsessive-compulsive disorder: Results from a large, naturalistic follow-up study. Journal of Affective Disorders, 203, 241-247. https://doi.org/10.1016/j.jad.2016.06.009

Document status and date:

Published: 01/10/2016

DOI:

10.1016/j.jad.2016.06.009

Document Version:

Publisher's PDF, also known as Version of record

Document license:

Taverne

Please check the document version of this publication:

- A submitted manuscript is the version of the article upon submission and before peer-review. There can be important differences between the submitted version and the official published version of record. People interested in the research are advised to contact the author for the final version of the publication, or visit the DOI to the publisher's website.

- The final author version and the galley proof are versions of the publication after peer review.

- The final published version features the final layout of the paper including the volume, issue and page numbers.

Link to publication

\footnotetext{
General rights rights.

- You may freely distribute the URL identifying the publication in the public portal. please follow below link for the End User Agreement:

www.umlib.nl/taverne-license

Take down policy

If you believe that this document breaches copyright please contact us at:

repository@maastrichtuniversity.nl

providing details and we will investigate your claim.
}

Copyright and moral rights for the publications made accessible in the public portal are retained by the authors and/or other copyright owners and it is a condition of accessing publications that users recognise and abide by the legal requirements associated with these

- Users may download and print one copy of any publication from the public portal for the purpose of private study or research.

- You may not further distribute the material or use it for any profit-making activity or commercial gain

If the publication is distributed under the terms of Article 25fa of the Dutch Copyright Act, indicated by the "Taverne" license above, 
Research paper

\title{
The relation between depressive and obsessive-compulsive symptoms in obsessive-compulsive disorder: Results from a large, naturalistic follow-up study
}

\author{
Judith Rickelt ${ }^{\mathrm{a}, \mathrm{b}, *}$, Wolfgang Viechtbauer ${ }^{\mathrm{a}}$, Ritsaert Lieverse ${ }^{\mathrm{a}, \mathrm{c}}$, Thea Overbeek ${ }^{\mathrm{c}}$, \\ Anton J. van Balkom ${ }^{\mathrm{d}, \mathrm{e}, \mathrm{f}}$, Patricia van Oppen ${ }^{\mathrm{d}, \mathrm{e}, \mathrm{f}}$, Odile A. van den Heuvel ${ }^{\mathrm{d}, \mathrm{g}}$, \\ Machteld Marcelis $^{\mathrm{a}, \mathrm{b}}$, Merijn Eikelenboom ${ }^{\mathrm{d}, \mathrm{e}}$, Lee Tibi ${ }^{\mathrm{h}}$, Koen RJ Schruers ${ }^{\mathrm{a}, \mathrm{c}, \mathrm{i}}$ \\ a Department of Psychiatry \& Neuropsychology, School for Mental Health and Neuroscience, Maastricht University, Maastricht, The Netherlands \\ ${ }^{\mathrm{b}}$ Institute for Mental Health Care Eindhoven (GGzE), Eindhoven, The Netherlands \\ ${ }^{c}$ Mondriaan Mental Health Center, Maastricht, The Netherlands \\ d Department of Psychiatry, VU University Medical Center (Vumc), Amsterdam, The Netherlands \\ e EMGO+, VU University Medical Center (Vumc), Amsterdam, The Netherlands \\ ${ }^{f}$ GGZ inGeest, Amsterdam, The Netherlands \\ ${ }^{g}$ Department of Anatomy \& Neurosciences, VUmc, Neuroscience Campus Amsterdam (NCA), VU/VUmc, Amsterdam, The Netherlands \\ h Psychology Department, Ben Gurion University, Be'er-Sheva, Israel \\ i Department of Health Psychology, University of Leuven, Belgium
}

\section{A R T I C L E I N F O}

\section{Article history:}

Received 11 April 2016

Received in revised form 28 May 2016

Accepted 3 June 2016

Available online 6 June 2016

Keywords:

Obsessive-compulsive disorder

Depression

Comorbidity

Longitudinal studies

\begin{abstract}
A B S T R A C T
Objective: Despite the frequent occurrence of depressive symptoms in obsessive-compulsive disorder $(\mathrm{OCD})$, little is known about the reciprocal influence between depressive and obsessive-compulsive symptoms during the course of the disease. The aim of the present study is to investigate the longitudinal relationship between obsessive-compulsive and depressive symptoms in OCD patients.

Method: We used the baseline and 1-year follow-up data of the Netherlands Obsessive Compulsive Disorder Association (NOCDA) study. In 276 patients with a lifetime diagnosis of obsessive-compulsive disorder, depressive and obsessive-compulsive symptoms were assessed at baseline and at one-year follow-up with the Beck Depression Inventory (BDI) and the Yale-Brown Obsessive Compulsive Symptom (Y-BOCS) scale. Relations were investigated using a cross-lagged panel design.

Results: The association between the severity of depressive symptoms at baseline and obsessive-compulsive symptoms at follow-up was significant $(\beta=0.244, \mathrm{p}<0.001)$, while the association between the severity of obsessive-compulsive symptoms at baseline and depressive symptoms at follow-up was not $(\beta=0.097, p=0.060)$. Replication of the analyses in subgroups with and without current comorbid major depressive disorder (MDD) and subgroups with different sequence of onset (primary versus secondary MDD) revealed the same results.

Limitations: There may be other factors, which affect both depressive and obsessive-compulsive symptoms that were not assessed in the present study.

Conclusion: The present study demonstrates a relation between depressive symptoms and the course of obsessive-compulsive symptoms in OCD patients, irrespective of a current diagnosis of MDD and the sequence of onset of OCD and MDD.
\end{abstract}

(c) 2016 Elsevier B.V. All rights reserved.

\section{Introduction}

Obsessive-compulsive disorder (OCD) is a disabling and often chronic psychiatric disorder which leads to significant impairment

\footnotetext{
*Correspondence to: GGzE t.a.v., Postbus 909, 5600 AX Eindhoven, The Netherlands.

E-mail address: judith.rickelt@maastrichtuniversity.nl (J. Rickelt).
}

in daily life and diminished well-being (Farris et al., 2013; Hollander et al., 2010; Albert et al., 2010; Eisen et al., 2006). About $0.5-3 \%$ of the general population develops OCD in their lifetime (Grabe et al., 2001; Kessler et al., 2012; Subramaniam et al., 2012). Comorbidity is the rule rather than the exception, with major depressive disorder (MDD) being one of the most frequent comorbid diagnoses (Lochner et al., 2014; Klein Hofmeijer-Sevink et al., 2013). Comorbidity rates differ largely due to methodological differences, but overall approximately one third of the patients 
with OCD suffer from a current comorbid MDD, and about twothird have lifetime comorbidity of MDD (Viswanath et al., 2012; Quarantini et al., 2011; Torres et al., 2006; Pinto et al., 2006; LaSalle et al., 2004). Moreover, many OCD patients suffer from depressive symptoms, but do not fulfill the diagnostic criteria for a depressive episode.

Depressive symptoms often are regarded as a consequence of the burden of OCD. OCD is associated with a decreased quality of life and an increased functional impairment in work, family and social life (Huppert et al., 2009). OCD patients spend more time thinking of the obsessions and performing compulsions, accompanied by anxiety, and thus experience less positive activities and emotions, which may lead to depressive symptoms. However, although several studies found a correlation between depressive symptoms and diminished quality of life as well as functional impairment, depressive symptoms appeared to be rather a mediating factor between the severity of the obsessive-compulsive symptoms and these factors than a consequence of them (Kugler et al., 2013; Storch et al., 2014).

Several studies found evidence for common genetic factors of obsessive-compulsive and depressive symptoms. MDD occurs more often in first-degree relatives of OCD patients compared to relatives of healthy controls and vice versa, which demonstrates the familial aggregation of this comorbidity (Carter et al., 2004; Goes et al.; 2012). In addition, Bolhuis et al. found that the cooccurrence of obsessive-compulsive and depressive symptoms is mainly explained by shared genetic factors while the contribution of non-shared environmental factors is considerably smaller (Bolhuis et al., 2014).

Despite the frequent occurrence of comorbid obsessive-compulsive and depressive symptoms, the treatment of comorbid depression in OCD is still a matter of debate. Some authors suggest to address also the depressive symptomatology while treating OCD (Olatunji et al., 2013; Abramowitz 2004; Rector et al., 2009), whereas others expect the depressive symptoms to improve along with the obsessive-compulsive symptoms, and recommend to focus on the treatment of the OCD only, without specific interventions addressing the depression (Anholt et al., 2011; Zandberg et al., 2015; Zitterl et al., 2000).

Further knowledge about the relationship between obsessivecompulsive and depressive symptoms may help to solve this debate. Most cross-sectional studies found a correlation between obsessive-compulsive and depressive symptoms in OCD patients (Besiroglu et al., 2007; Abramowitz and Foa, 2000; Demal et al., 1996) but no conclusions about the direction of this relationship can be drawn from correlational analyses alone. To that end, obsessive-compulsive and depressive symptoms have to be studied over time.

The present study aims to investigate the longitudinal relationship between obsessive-compulsive and depressive symptoms in OCD patients during the disease course. First, we studied the influence of comorbid depression on the severity and the course of OCD. We hypothesized that comorbid depression is associated with more severe obsessive-compulsive symptoms and a worse course. Second, we investigated the direction of the longitudinal relationship between obsessive-compulsive and depressive symptoms, to examine whether obsessive-compulsive symptoms lead to depressive symptoms or vice versa. Based on the literature, we expected a reciprocal influence with a greater impact of obsessive-compulsive symptoms on the depressive symptoms than vice versa. Third, we studied whether the relationship between obsessive-compulsive and depressive symptoms differs between patients with and without a diagnosis of current MDD, and between patients who first had MDD and developed OCD later in life (primary depression) and those who developed MDD during the course of the OCD (secondary depression). We hypothesized a greater influence of depressive symptoms on the obsessive-compulsive symptoms in OCD patients with a comorbid depression and in patients with primary MDD.

\section{Methods}

\subsection{Participants}

Data were obtained from the NOCDA study (Schuurmans et al., 2012). The NOCDA study is an ongoing longitudinal naturalistic multicenter cohort study which examines the course of OCD in 419 OCD patients. Patients were included between September 2005 and November 2009 at one of seven participating mental health care centers in the Netherlands. All referred patients aged 18 years and older with a lifetime diagnosis of OCD were asked for permission to be contacted for research purposes, irrespective of the stage of the disease, the severity of the obsessive-compulsive symptoms and comorbid diagnoses. The only exclusion criterion was an inadequate understanding of the Dutch language for the completion of the interviews and questionnaires.

Six hundred eighty-seven patients with OCD were invited to participate in the study. Ninety-seven subjects (28.7\%) refused tot participate, 32 subjects $(4.7 \%)$ were not able to participate due to mental or physical health problems and 39 (5.7\%) subjects could not be contacted. Subjects who participated in the study and eligible patients who chose not to participate did not differ regarding sex, age or years of education (Schuurmans et al., 2012). At one of the participating centers (Academic Anxiety Center, PsyQ Maastricht) the subjects who participated in the NOCDA study were compared to those who did not participate regarding clinical characteristics, yielding no significant differences (results not published).

All included patients gave written informed consent to participate. The study is approved by the Medical Ethical Committee VUmc (Amsterdam) and the local Medical Ethical Committees of all participating centers.

The present study is based on the data from the semi-structured interviews and the self-administered questionnaires of the baseline measurement and the self-administered questionnaires of the follow-up after one year.

\subsection{Measures}

At baseline, we used the Structured Clinical Interview for the DSM-IV-TR (SCID-I/P) to assess the axis-I morbidity (First et al., 1999). Among others, current and lifetime OCD as well as current and lifetime MDD were diagnosed according to the criteria of the DSM-IV-TR (APA, 2000). We assessed retrospectively the age of onset of the OCD and the MDD using the SCID-I/P. Age of onset was defined by the age of the participant when the DSM-IV-TR criteria of OCD and MDD were first met. If the onset of the lifetime diagnosis of MDD preceded the onset of lifetime diagnosis of OCD, we defined it as primary depression. If the lifetime onset of the MDD succeeded the onset of the OCD, we defined it as secondary depression. If the criteria of OCD and MDD were met at the same age, we considered it as simultaneous onset.

The severity of obsessive-compulsive symptoms was measured at baseline using the clinician rated Yale-Brown Obsessive Compulsive Symptom (Y-BOCS) severity scale (Goodman et al., 1989a, 1989b) and at one-year follow-up using the self-rate version of the Y-BOCS (Steketee et al., 1996). The severity of depressive symptoms was measured at baseline and at one-year follow-up by the Beck Depression Inventory (BDI, Beck et al., 1961). 


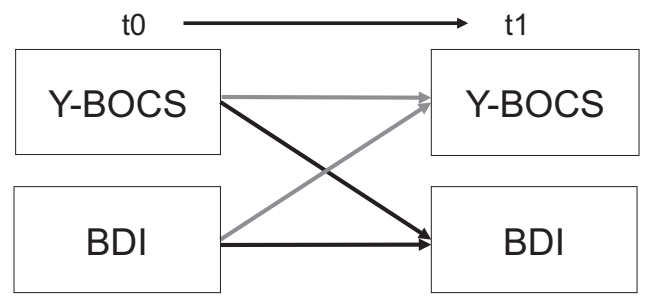

Fig. 1. Cross-lagged panel design. $\longrightarrow$ Regression Y-BOCS t0 - BDI t1, corrected for $\mathrm{BDI}$ t0, leading tot regression coefficient beta $\beta_{\mathrm{Y}-\mathrm{BOCS}}$ t0 $-\mathrm{BDI} \mathrm{t} 1 . \longrightarrow$ Regression BDI t0 - Y-BOCS $\mathrm{t} 1$, corrected for Y-BOCS t0, leading tot regression coefficient beta $\beta$ BDI to - Y-BOCS t1.

\subsection{Analysis}

Independent samples t-test were used to test for differences between participants with and without comorbid MDD at baseline with respect to their Y-BOCS scores at t0 and t1. Analyses to test for differences in the baseline characteristics of participants who dropped-out versus those who continued their participation were performed using Pearson chi square tests for sex, current/lifetime diagnoses and antidepressants medication, a Mann-Whitney $U$ test for age, and independent samples $t$-tests for Y-BOCS scores, BDI scores and frequency of contacts with mental health care professionals. The differences between the treatment of participants with and without a comorbid MDD were performed using Pearson chi square tests (antidepressant medication, any contact with mental health care professionals in the last 12 months) and independent samples t-test (frequency of contacts with mental health care professionals in the last 12 months).

To examine the direction of the relation between obsessivecompulsive symptoms and the depressive symptoms, we used a cross-lagged panel (CLP) analysis. After standardizing the Y-BOCS and BDI variables, we fitted the path model shown in Fig. 1, where the Y-BOCS and BDI scores at follow-up (t1) are regressed on the scores at baseline (t0) simultaneously. Of particular interest here are the cross-lagged paths (i.e., Y-BOCS t $0 \rightarrow$ BDI $t 1$ and BDI $t 0 \rightarrow Y$ BOCS $\mathrm{t} 1$ ) that provide evidence about the direction of the relationship between two variables (e.g., when one coefficient is large and significant and the other is not). Moreover, we directly tested whether the strength of the cross-lagged coefficients differed by fitting a path model with the cross-lagged paths constrained to be equal and compared this to the unconstrained model using a chi-square test with one degree of freedom. The path models were fitted using maximum likelihood (ML) estimation. To examine whether this relation differs between participants with and without a current MDD at baseline, we repeated these analyses for these subgroups. We also performed a CLP analysis with the subgroups of patients in which the depressive disorder preceded the obsessive-compulsive disorder (primary depression) and those in which the onset of MDD succeeded the onset of OCD (secondary depression) to examine whether the direction of the relation between obsessive-compulsive and depressive symptoms differs between these groups.

If $20 \%$ or more of the items were missing for a particular scale for a given subject (i.e., 2 or more items on the Y-BOCS and/or 4 or more items on the $\mathrm{BDI}$ ), the data were considered unreliable and the subject was excluded from the analysis. If fewer items were missing, we left the scale total as missing and then fitted the path models using full information maximum likelihood (FIML). Analyses were carried out with SPSS (version 20) and R (version 3.2.2), using the lavaan package for the path analyses (Rosseel, 2012).
Table 1

Characteristics of the sample at baseline and 1-year follow-up.

\begin{tabular}{|c|c|c|}
\hline & Baseline $(n=419)$ & Follow-up $(\mathrm{n}=286)$ \\
\hline Mean age & 37 years (18-79) & 38 years $(19-80)$ \\
\hline Male & $\mathrm{n}=185(44.2 \%)$ & $\mathrm{n}=119(41.6 \%)$ \\
\hline Female & $\mathrm{n}=234(55.8 \%)$ & $\mathrm{n}=167(58.4 \%)$ \\
\hline OCD at baseline current & $\mathrm{n}=382(91.2 \%)$ & $\mathrm{n}=257(89.9 \%)$ \\
\hline OCD at baseline lifetime & $\mathrm{n}=419(100 \%)$ & $\mathrm{n}=286(100 \%)$ \\
\hline \multicolumn{3}{|l|}{ Comorbidity at baseline } \\
\hline Any current comorbidity & $\mathrm{n}=223(53.2 \%)$ & $\mathrm{n}=163(57 \%)$ \\
\hline Any lifetime comorbidity & $\mathrm{n}=326(77.8 \%)$ & $\mathrm{n}=227(79.4 \%)$ \\
\hline $\begin{array}{l}\text { Major depressive disorder at base- } \\
\text { line current }\end{array}$ & $\mathrm{n}=72(17.2 \%)$ & $\mathrm{n}=50(17.5 \%)$ \\
\hline $\begin{array}{l}\text { Major depressive disorder at base- } \\
\text { line lifetime }\end{array}$ & $\mathrm{n}=237(56.6 \%)$ & $\mathrm{n}=168(58.7 \%)$ \\
\hline \multicolumn{3}{|l|}{$\begin{array}{l}\text { Other comorbid diagnoses at base- } \\
\text { line (current) }\end{array}$} \\
\hline Dysthymic disorder & $\mathrm{n}=22(5.3 \%)$ & $\mathrm{n}=12(4.2 \%)$ \\
\hline Bipolar disorder & $\mathrm{n}=4(1 \%)$ & $\mathrm{n}=3(1 \%)$ \\
\hline Social phobia & $\mathrm{n}=75(17.9 \%)$ & $\mathrm{n}=57(19.9 \%)$ \\
\hline $\begin{array}{l}\text { Panic Disorder with/ without } \\
\text { agoraphobia }\end{array}$ & $\mathrm{n}=13(3.1 \%)$ & $\mathrm{n}=27(9.4)$ \\
\hline $\begin{array}{l}\text { Agoraphobia without panic } \\
\text { disorder }\end{array}$ & $\mathrm{n}=7(1.7 \%)$ & $\mathrm{n}=4(1.4 \%)$ \\
\hline Generalized anxiety disorder & $\mathrm{n}=38(9.1 \%)$ & $\mathrm{n}=30(10.5)$ \\
\hline Posttraumatic stress disorder & $\mathrm{n}=13(3.1 \%)$ & $\mathrm{n}=11(3.8)$ \\
\hline Specific phobia & $\mathrm{n}=35(8.4 \%)$ & $\mathrm{n}=27(9.4 \%)$ \\
\hline $\begin{array}{l}\text { Anxiety disorder not otherwise } \\
\text { specified }\end{array}$ & $\mathrm{n}=2(0.5 \%)$ & $\mathrm{n}=2(0.7)$ \\
\hline $\begin{array}{l}\text { Any psychotic disorder (incl. } \\
\text { schizophrenia) }\end{array}$ & $\mathrm{n}=10(2.4 \%)$ & $\mathrm{n}=5(1.7)$ \\
\hline Substance related disorders & $\mathrm{n}=20(4.8 \%)$ & $\mathrm{n}=11(3.8 \%)$ \\
\hline Somatoform disorders & $\mathrm{n}=22(5.3 \%)$ & $\mathrm{n}=18(6.3 \%)$ \\
\hline Eating disorders & $\mathrm{n}=19(4.5 \%)$ & $\mathrm{n}=17(5.9 \%)$ \\
\hline \multicolumn{3}{|l|}{ Measures } \\
\hline YBOCS mean & $20(0-40$, SD 8.1$)$ & $15.9(0-40$, SD 8.8) \\
\hline BDI mean & $\begin{array}{l}15.3(0-51, S D \\
10.1)\end{array}$ & $12.6(0-56$, SD 10.6) \\
\hline \multicolumn{3}{|l|}{ Treatment } \\
\hline $\begin{array}{l}\text { Current antidepressant } \\
\text { medication }\end{array}$ & $\mathrm{n}=257(61.3 \%)$ & $\mathrm{n}=172(60.1 \%)$ \\
\hline Any contact with mental & $\begin{array}{l}\text { in the last } \\
6 \text { months }\end{array}$ & in the last 12 months \\
\hline health care professionals & $\begin{array}{l}\mathrm{n}=348(83.1 \%) \\
\text { mean }=9 \\
\text { sessions }\end{array}$ & $\begin{array}{l}\mathrm{n}=263(92 \%) \\
\text { mean }=16.3 \text { sessions }\end{array}$ \\
\hline & $(0-150$, SD 12.1) & $(0-260$, SD 26) \\
\hline
\end{tabular}

\section{Results}

\subsection{Clinical characteristics}

Demographic and clinical characteristics of the sample are shown in Table 1. At baseline, 419 participants were included. At follow-up after one year, 133 participants (31.7\%) dropped out, leaving 286 participants. There were no significant differences at baseline between participants who dropped out and participants who continued participation regarding age, sex, current and lifetime diagnosis of OCD, current and lifetime diagnosis of MDD, other comorbidities, severity of obsessive-compulsive symptoms, severity of depressive symptoms, antidepressant medication and previous contacts with mental health care professionals.

At baseline, 72 participants (17.2\%) had a current MDD. Within the group that participated in the follow-up, 50 participants (17.5\%) had a current MDD at baseline. There was no difference in the use of antidepressant medication, contact with a mental health care professional in the last 12 months and the frequency of contacts with a mental health care professional in the last 12 months between participants with and without a comorbid MDD.

Baseline Y-BOCS and BDI total scores were available for 414 and 398 participants, respectively, and for 283 participants at followup. Thirty-four percent of the participants $(n=143)$ were excluded 


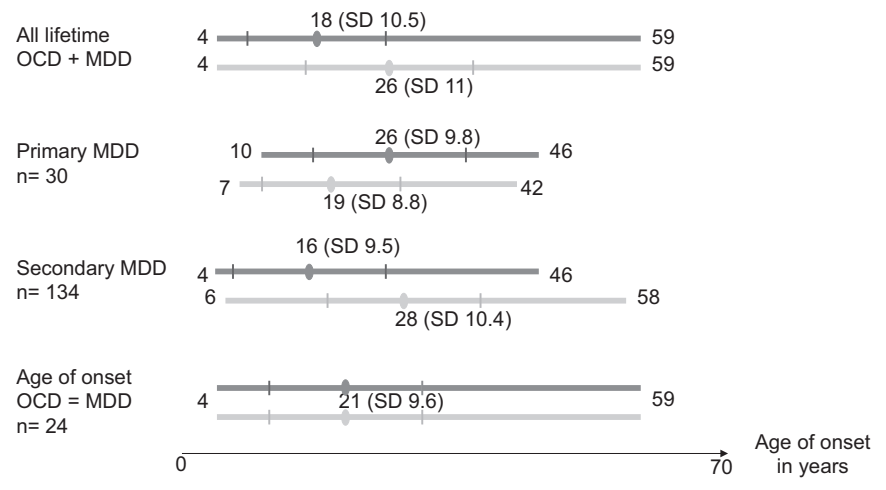

Fig. 2. Sequence of age of onset of OCD and MDD. Age of onset OCD with mean age of onset. Age of onset MDD with mean age of onset.

from the CLP analysis because of missing Y-BOCS and/or BDI scores at baseline or follow-up due to drop out $(n=133)$ or incomplete questionnaires $(n=10)$, leaving 276 participants.

\subsection{Temporal sequencing}

The age of onset of OCD and MDD was available in 377 of the 419 participants with lifetime OCD and in 207 of the 237 participants with lifetime MDD. The mean age of onset of OCD was 18 years (range 4-59 years, SD 9.6), and the mean age of onset of MDD was 26 years (range 4-59, SD 9.6). Of the participants with comorbid lifetime MDD ( $\mathrm{n}=237)$, the age of onset of both OCD and MDD was available in 188 participants (79.3\%). In 30 participants (16\%) MDD preceded OCD (primary MDD), in 134 participants (71\%) OCD preceded MDD (secondary MDD), and in 24 participants (13\%) MDD and OCD occurred at the same age. The sequence and age of onset are shown in Fig. 2.

For the CLP analyses of the groups of primary and secondary depression, the Y-BOCS and BDI at both baseline and 1-year follow-up were available in 127 participants with known age of onset of OCD and MDD. Eighteen participants (14.2\%) had a primary MDD, 94 participants (74\%) had a secondary MDD, and in 15 participants (11.8\%) OCD and MDD had the onset at the same age.

\subsection{Comorbid major depressive disorder}

To examine the relationship between current Major Depressive Disorder (MDD) at baseline and the severity of the obsessivecompulsive symptoms at baseline and follow-up, we compared the mean Y-BOCS score of the depressed participants with the mean Y-BOCS score of the non-depressed participants.

In the group with a current comorbid MDD, the mean Y-BOCS score at baseline was 24.5 (SD 7.6). Non-depressed participants had a mean baseline Y-BOCS score of 18.9 (SD 7.9). This difference was statistically significant $(\mathrm{p}<0.001)$. Participants with current MDD at baseline also had a significantly higher mean score on the
Y-BOCS severity scale at the one-year follow-up assessment, that is, 18.7 (SD 10.4) versus 15.4 (SD 8.4), respectively $(\mathrm{p}=0.017)$.

\subsection{Relation between obsessive-compulsive and depressive symptoms}

To examine the relation between obsessive-compulsive and depressive symptoms, we performed the CLP analysis for the whole group and different subgroups. The results are shown in Table 2.

In all analyses, the relationship between BDI at baseline and Y-BOCS at follow-up was significant, while the association between the Y-BOCS score at baseline and the BDI score at follow-up was not.

When we compared the strength of both regression paths directly, they did not differ significantly, except in the group of primary MDD. In this subgroup, the depressive symptoms had a significantly stronger effect on the obsessive-compulsive symptoms than vice versa.

\section{Discussion}

In the present longitudinal study we investigated major depressive disorder (MDD) and depressive symptoms in obsessivecompulsive disorder (OCD), using data from the NOCDA study which to our knowledge is the largest longitudinal cohort study in OCD. We found a significant association between the severity of depressive symptoms at baseline and obsessive-compulsive symptoms one year later, while the relation between the severity of obsessive-compulsive symptoms at baseline and depressive symptoms at follow-up was not significant. This effect was observed in all groups, irrespective of a comorbid MDD or whether the MDD preceded or succeeded the OCD.

There are a few prospective longitudinal studies, which address the direction of the relation between obsessive-compulsive and depressive symptoms. A twin study in adolescents with OCD investigated the longitudinal relationship between obsessive-compulsive and depressive symptoms. They concluded that obsessivecompulsive symptoms predict depressive symptoms two years later to a similar extent to which depressive symptoms predict obsessive-compulsive symptoms. There are several methodological differences that may account for the partially different results. The participants were adolescent twins, the obsessive-compulsive symptoms and depressive symptoms were measured by the Spence Children's Anxiety Scale and the Short Mood and Feelings Questionnaire, and the study period was two years. In addition, the study was designed as a twin study with the primary aim to investigate the influence of genetic versus environmental factors on the comorbidity of OCD and MDD (Bolhuis et al., 2014).

A treatment study which investigated the mediators of change in behavioral versus cognitive therapy in OCD patients found that

Table 2

Regression coefficients per subgroup.

\begin{tabular}{|c|c|c|c|c|c|}
\hline & \multicolumn{2}{|c|}{ Y-BOCS t0 - BDI t1 } & \multicolumn{2}{|c|}{ BDI t0 - Y-BOCS t1 } & \multirow[t]{2}{*}{ Test of $\beta$ Y-BOCS t0-BDI $t 1=\beta$ BDI t0-Y-BOCS $t 1$} \\
\hline & $\mathrm{B}$ & $\mathrm{p}$ & $\beta$ & $\mathrm{P}$ & \\
\hline All participants $(n=276)$ & $\beta=0.097$ & $\mathrm{p}=0.060$ & $\beta=0.244$ & $\mathrm{p}<0.001^{* *}$ & $\mathrm{p}=0.084$ \\
\hline Current MDD $(n=50)$ & $\beta=0.127$ & $\mathrm{p}=0.275$ & $\beta=0.466$ & $\mathrm{p}=0.001^{* *}$ & $\mathrm{p}=0.083$ \\
\hline No current MDD $(n=226)$ & $\beta=0.099$ & $\mathrm{p}=0.098$ & $\beta=0.191$ & $\mathrm{p}=0.003^{* *}$ & $\mathrm{p}=0.328$ \\
\hline Primary MDD $(\mathrm{n}=18)$ & $\beta=-0.036$ & $\mathrm{p}=0.877$ & $\beta=0.719$ & $\mathrm{p}<0.001^{* *}$ & $\mathrm{p}=0.034^{*}$ \\
\hline Secondary MDD $(n=94)$ & $\beta=0.154$ & $\mathrm{p}=0.093$ & $\beta=0.261$ & $\mathrm{p}=0.014$ & $\mathrm{p}=0.504$ \\
\hline
\end{tabular}

\footnotetext{
* Significant at $\mathrm{p}<0.05$
}

Significant at $\mathrm{p}<0.01$ 
a reduction in depressed mood mediated changes in OCD symptom severity in both behavioral and cognitive therapy (Olatunji et al., 2013). Other research contradicts this conclusion. Anholt et al. (2011) investigated the relation between obsessive-compulsive and depressive symptoms in patients following different treatment conditions specific for OCD. This study was recently replicated for exposure with response prevention in combination with a serotonergic reuptake inhibitor (Zandberg et al., 2015). Both studies found that obsessive-compulsive symptoms fully mediated changes in depressive symptoms while depressive symptoms only partially mediated OCD symptoms. The studies differ from our study in several aspects. They included patients with clinical symptoms of OCD with a higher mean Y-BOCS severity score for different therapeutic interventions. In contrast, our study used a naturalistic design and included OCD patients irrespective of the state or severity of the $O C D$ leading to a greater range of $O C D$ symptom severity. Both clinical trials had more stringent inclusion criteria and excluded certain comorbidities, while the present study did not.

In the present study, the comorbid diagnosis of MDD was associated with more severe obsessive-compulsive symptoms at the same time as well as one year later. This is in line with several cross-sectional studies that reported more severe obsessive-compulsive symptoms in OCD patients with comorbid MDD (Demal et al., 1996; Viswanath et al., 2012; Quarantini et al., 2011; Karadag et al., 2006; Tükel et al., 2006) although no conclusion regarding the prognostic impact of comorbid MDD can be drawn based on these findings. In a 15-year prospective follow-up study on the course of OCD, Marcks et al. (2011) found that MDD at intake was associated with a decreased likelihood of recovery and remission of OCD.

Because of the reported significant effect of MDD on the severity of the OCD symptoms during the course of the disease, we investigated whether the effect of depressive symptoms on the disease course could be explained by the group of patients with a current comorbid MDD at baseline. Our results show that this was not the case: the depressive symptoms were associated with the course of the obsessive-compulsive symptoms as well in OCD patients with MDD as in OCD patients without MDD.

Some authors suggest that the sequence of onset of OCD and MDD may influence the direction of the relation between both disorders, expecting that obsessive-compulsive symptoms have a greater influence on comorbid depressive symptoms when the depression developed after the onset of OCD (Zandberg et al., 2015; Zitterl et al., 2000; Besiroglu et al., 2007). Several clinical studies found that MDD succeeded the OCD in the majority of cases (Subramaniam et al., 2012; Zitterl et al., 2000; Ruscio et al., 2010; Millet et al., 2004). Also in the present study, seventy-one percent of the patients first suffered from OCD and developed MDD later in life. In the small group with primary MDD, the depressive symptoms had a significant stronger effect on the obsessive-compulsive symptoms than vice versa. But also in the group which developed MDD during the course of OCD, we found a significant relation between depressive symptoms at baseline and obsessive-compulsive symptoms at follow-up while the opposite association was not significant.

These results suggest that the direction of the relation is not influenced by the sequence of onset. However, both OCD and MDD often have a fluctuating course with variations in the severity of symptoms and periods of remission and relapse (Marcks et al., 2011; Eisen et al., 2013; Judd et al., 1998) while temporal sequencing solely assesses the order of the age of onset of the first episode. In addition, a factor that causes a certain disorder may not necessarily be the same as the one that leads to relapse, deterioration or chronicity.

Different underlying mechanisms may explain how depressive symptoms may provoke, maintain, or modulate obsessive-compulsive symptoms in OCD. Depressed patients may have less energy to resist the compulsions which can maintain the obsessivecompulsive symptoms and worsen the prognosis. Depressive cognitions of self-blame, guilt, or catastrophic interpretations may be applied to the occurrence and the content of the obsessions, making them more salient and thus increasing the need to carry out compulsions. Rumination, worries, and doubting are frequent symptoms in depressive patients and may lead to a heightened state of anxiety. In people prone to $\mathrm{OCD}$, attempts to reduce this anxiety may result in an increase in compulsive behavior.

In conclusion, the present study demonstrates a relation between depressive symptoms and the course of obsessive-compulsive symptoms in OCD patients, irrespective of a current diagnosis of MDD and the sequence of onset of OCD and MDD. The effect of the obsessive-compulsive symptoms on the course of the depressive symptoms is less clear. Our results did not demonstrate a significant relation between obsessive-compulsive symptoms and the course of the depressive symptoms, but cannot exclude it. When the strengths of both directions of the relation between obsessive-compulsive and depressive symptoms were compared directly, the difference was not significant except in the small group of participants with comorbid MDD preceding the OCD.

The results suggest a causal relationship between the severity of depressive symptoms and the course of obsessive-compulsive symptoms. However, theoretically, there might be other factors affecting both depressive and obsessive-compulsive symptoms, such as comorbidity, antidepressant medication or psychotherapy. No participants were excluded due to comorbidity (in fact more than half of the participants had at least one comorbid diagnosis). This was an explicit choice to ensure the generalizability of our results, as comorbidity is common in OCD. The most frequent comorbid disorders were MDD and diverse anxiety disorders but overall, the comorbid diagnoses were quite heterogeneous. It therefore seems unlikely that they would explain our results.

More than half of the participants were on antidepressant medication and more than $90 \%$ had contacts with a mental health care professional between baseline and follow-up. Antidepressant medication and the contacts with mental health care professionals did not differ between participants with and without MDD. However, we did not assess the therapeutic interventions and the reason for the consultations, which is a clear limitation.

Further limitations are the assessment of the obsessive-compulsive symptoms and the definition of the age of onset. The age of onset was assessed retrospectively and measured in years. For the measurement of the obsessive-compulsive symptoms, we used the clinician-rated version of the Y-BOCS at baseline and the self-report version at follow-up. The follow-up was less extensive than the baseline assessment and contained only self-report questionnaires to limit the patients' study burden. However, the selfreport Y-BOCS is a reliable and valid measure, which shows strong convergent validity with the interview Y-BOCS (Steketee et al., 1996).

Another limitation is the possibility of a selection bias. Patients were recruited from outpatient clinics and treatment programs for anxiety and obsessive-compulsive disorders. Probably, there were also patients with both MDD and OCD who were referred to an outpatient clinic or treatment program for mood disorders, and hence were not included in the present study. This might explain the mild to moderate severity of the depressive symptoms and the prevalence of current MDD being eighteen percent, which is quite low compared to the literature. On the other hand, the lifetime prevalence of MDD in our sample was $57 \%$, which is in line with most of the lifetime prevalence rates reported in the literature (Quarantini et al., 2011; Pinto et al., 2006; Zitterl et al., 2000; Marcks et al., 2011). 
Finally, the study had a $31 \%$ dropout at follow-up. We dealt with missing data using an estimation method (FIML) that is appropriate when the missing data are missing at random (MAR). Estimation or imputation methods could not be applied reliably to the dropouts for their data is likely not missing at random (nonignorable missingness). However, we do not expect that the missing data affected our results, because the dropouts and completers did not differ in their clinical characteristics at baseline. In addition, dropouts were taken into account in the design of the study (Schuurmans et al., 2012), and even after dropout the analyses are based on the large sample size of 286 participants.

There are few prospective longitudinal studies that address the relation between obsessive-compulsive and depressive symptoms and to our knowledge the present study is the first one which studied a naturalistic course in adult OCD patients. Replication of the study in other clinical or population-based samples may answer the question whether the results can be generalized to other groups than OCD patients. Future studies should also focus on possible factors that mediate the reciprocal influence of obsessivecompulsive and depressive symptoms, such as shared vulnerabilities or common biological mechanisms.

The findings of the present study have several clinical implications. Considering the high prevalence of lifetime and current MDD in OCD patients and the influence of the depressive symptoms on the course of the obsessive-compulsive symptoms, depressive symptoms should be routinely assessed in OCD patients. Our results do not confirm the assumption that in OCD patients the depressive symptoms improve along with the obsessivecompulsive symptoms. Instead, depressive symptoms may maintain or worsen OCD symptoms. Therefore, we recommend that treatment also needs to address the depression. There are examples of treatment programs that combine interventions from cognitive behavioral therapy for depression and $O C D$, with positive results (Abramowitz, 2004; Arco, 2015; Rector et al., 2009). Pharmacotherapy with serotonergic antidepressants is another treatment option which addresses both disorders and can be combined with cognitive behavioral therapy for OCD (Romanelli et al., 2014; Soomro et al., 2008).

\section{Acknowledgements}

The research infrastructure needed to complete the measurements at baseline and follow-up (including personnel and materials) is financed almost exclusively by the participating organizations of the Netherlands Obsessive Compulsive Disorder Association (Academic department VU Medical Center/ GGZinGeest, Amsterdam, The Netherlands; Innova Research Center, Mental Health Care Institute GGZ Centraal, Marina de Wolf Anxiety Research Center, Ermelo, The Netherlands; Center for Anxiety Disorders "Overwaal", Lent, The Netherlands; Dimence, GGZ Overijssel, The Netherlands; Department of Psychiatry, Leiden University Medical Center, Leiden, The Netherlands; Vincent van Gogh Institute Mental Health Care Center Noord- en Midden-Limburg, Venray, The Netherlands; Academic Anxiety Center, PsyQ Maastricht University, Division Mental Health and Neuroscience, Maastricht, The Netherlands), except for the fieldwork coordinator, who was financed for a duration of one year by a research Grant from Stichting Steun (Grant no: ST180505.Le).

\section{References}

Abramowitz, J.S., 2004. Treatment of obsessive-compulsive disorder in patients who have comorbid depression. J. Clin. Psychol. 60, 1133-1141.

Abramowitz, J.S., Foa, E.B., 2000. Does comorbid major depressive disorder influence outcome of exposure and response prevention for OCD? Behav. Ther 31, 795-800.

Albert, U., Maina, G., Bogetto, F., Chiarle, A., Mataix-Cols, D., 2010. Clinical predictors of health-related quality of life in obsessive-compulsive disorder. Compr. Psychiatry 51 (2), 193-200.

American Psychiatric Association, 2000. Diagnostic and Statistical Manual of Mental Disorders - Text Revision: DSM-IV-TR. 4th ed. Washington, D.C.

Anholt, G.E., Aderka, I.M., van Balkom, A.J., Smit, J.H., Hermesh, H., de Haan, E., van Oppen, P., 2011. The impact of depression on the treatment of obsessivecompulsive disorder: results from a 5-year follow-up. J. Affect. Disord. 135 (13), 201-207.

Arco, L., 2015. A case study in treating chronic comorbid obsessive-compulsive disorder and depression with behavioral activation and pharmacotherapy. Psychotherapy 52 (2), 278-286.

Beck, A.T., Ward, C.H., Mendelson, M., Mock, J., Erbaugh, J., 1961. An inventory for measuring depression. Arch. Gen. Psychiatry 4 (6), 561-567.

Besiroglu, L., Uguz, F., Saglam, M., Agargun, M.Y., Cilli, A.S., 2007. Factors associated with major depression occurring after the onset of obsessive-compulsive disorder. J. Affect. Dis. 102, 73-79.

Bolhuis, K., McAdams, T.A., Monzani, B., Gregory, A.M., Mataix-Cols, D., Stringaris, A., Eley, T.C., 2014. Aetiological overlap between obsessive-compulsive and depressive symptoms: a longitudinal twin study in adolescents and adults. Psychol. Med. 44, 1439-1449.

Carter, A.S., Pollock, R.A., Suvak, M.K., Pauls, D.L., 2004. Anxiety and major depression comorbidity in a family study of obsessive-compulsive disorder. Depression Anxiety 20, 165-174.

Demal, U., Zitterl, W., Lenz, G., Zapotoczky, H.G., Zitterl-Eglseer, K., 1996. Obsessivecompulsive disorder and depression - First results of a prospective study on 74 patients. Prog. Neuropsychopharmacol. Biol. Psychiatry 20, 801-813.

Eisen, J.L., Mancebo, M.A., Pinto, A., Coles, M.E., Pagano, M.E., Stout, R., Rasmussen, S.A., 2006. Impact of obsessive-compulsive disorder on quality of life. Compr. Psychiatry 47, 270-275.

Eisen, J.L., Sibrava, N.J., Boisseau, C.L., Mancebo, M.C., Stout, R.L., Pinto, A., Rasmussen, S.A., 2013. Five-year course of obsessive-compulsive disorder: predictors of remission and relapse. J. Clin. Psychiatry 74 (3), 233-239.

Farris, S.G., McLean, C.P., van Meter, P.E., Blair Simpson, H., Foa, E.B., 2013. Treatment response, symptom remission, and wellness in obsessive-compulsive disorder J. Clin. Psychiatry 74 (7), 685-690.

First, M.B., Spitzer, R.L., Gibbon, M., Williams, J.B.W., 1999. Structured Clinical Interview for DSM-IV Axis I Disorders - Patient Edition (Scid-I/P, Version 2.0), Biometrics Research. New York States Psychiatric Institute, New York.

Goes, F.S., McCusker, M.G., Bienvenu, O.J., MacKinnon, D.F., Mondimore, F.M., Schweizer, B., National Institute of Mental Health Genetics Initiative Bipolar Disorder Consortium, DePaulo, J.R., Potash, J.B., 2012. Co-morbid anxiety disorders in bipolar disorder and major depression: familial aggregation and clinical characteristics of comorbid panic disorder, social phobia, specific phobia and obsessive-compulsive disorder. Psychol. Med. 42 (7), 1449-1459.

Goodman, W.K., Price, L.H., Rasmussen, S.A., Mazure, C., Delgado, P., Heninger, G.R. Charney, D.S., 1989a. The yale-brown obsessive compulsive scale. II. Validity. Arch. Gen. Psychiatry 46, 1012-1016.

Goodman, W.K., Price, L.H., Rasmussen, S.A., Mazure, C., Fleischmann, R.L., Hill, C.L., Heninger, G.R., Charney, D.S., 1989b. The yale-brown obsessive compulsive scale. I. Development, use, and reliability. Arch. Gen. Psychiatry 46, 1006-1011.

Grabe, H.J., Meyer, C., Hapke, U., Rumpf, H.J., Freyberger, H.J., Dilling, H., John, U., 2001. Lifetime-comorbidity of obsessive-compulsive disorder and subclinical obsessive-compulsive disorder in Northern Germany. Eur. Arch. Psychiatry Clin. Neurosci. 251, 130-135.

Hollander, E., Stein, D.J., Fineberg, N.A., Marteau, F., Legault, M., 2010. Quality of life outcomes in patients with obsessive-compulsive disorder: relationship to treatment response and symptom relapse. J. Clin. Psychiatry 71 (6), 784-792.

Huppert, J.D., Blair Simpson, H., Nissenson, K.J., Liebowith, M.R., Foa, E.B., 2009. Quality of life and functional impairment in obsessive-compulsive disorder: a comparison of patients wit hand without comorbidity, patients in remission and healthy controls. Depression Anxiety 26 (1), 39-45.

Judd, L.L., Akiskal, H.S., Maser, J.D., Zeller, P.J., Endicott, J., Coryell, W., Paulus, M.P. Kunovac, J.L., Leon, A.C., Mueller, T.I., Rice, J.A., Keller, M.B., 1998. A prospective 12-year study of subsyndromal and syndromal depressive symptoms in unipolar major depressive disorders. Arch. Gen. Psychiatry 55, 694-700.

Karadag, F., Oguzhanoglu, N.K., Özdel, O., Atesci, F.C., Amuk, T., 2006. OCD symptom in a sample of Turkish patients: a phenomenological picture. Depression Anxiety $23,145-152$.

Kessler, R.C., Petukhova, M., Sampson, M.A., Zaslavsky, A.M., Wittchen, H.U., 2012 Twelve-month and lifetime prevalence and lifetime morbid risk of anxiety and mood disorders in the United States. Int. J. Methods Psychiatr. Res. 21 (3), $169-184$.

Klein Hofmeijer-Sevink, M., van Oppen, P., van Megen, H.J., Batelaan, N.M., Cath, D. C., van der Wee, N.J.A., van den Hout, M.A., van Balkom, A.J., 2013. Clinical relevance of comorbidity in obsessive-compulsive disorder: the Netherlands OCD Association study. J. Affect. Dis. 150, 847-854.

Kugler, B.B., Lewin, A.B., Phares, V., Geffken, G.R., Murphy, T.K., Storch, E.A., 2013. Quality of life in obsessive-compulsive disorder: the role of mediating variables. Psychiatr. Res. 206, 43-49.

LaSalle, V.H., Cromer, K.R., Nelson, K.N., Kazuba, D., Justement, L., Murphy, D.L., 2004. Diagnostic interview assessed neuropsychiatric disorder comorbidity in 334 individuals with obsessive-compulsive disorder. Depression Anxiety 19, 163-173. 
Lochner, C., Fineberg, N.A., Zohar, J., van Ameringen, M., Juven-Wetzler, A., Altamura, A.C., Cuzen, N.L., Hollander, E., Denys, D., Nicolini, H., Dell'Osso, B., Pallanti, S., Stein, D.J., 2014. Comorbidity in obsessive-compulsive disorder (OCD): a report from the International College of Obsessive-Compulsive Spectrum Disorders (ICOCS). Compr. Psychiatry 55 (7), 1513-1519.

Marcks, B.A., Weisberg, R.B., Dyck, I., Keller, M.B., 2011. Longitudinal course of obsessive-compulsive disorder in patients with anxiety disorders: a 15-year prospective follow-up study. Compr. Psychiatry 52, 670-677.

Millet, B., Kochman, F., Gallarda, T., Krebs, M.O., Demonfaucon, F., Barrot, I., Bourdel, M.C., Olié, J.P., Loo, H., Hantouche, E.G., 2004. Phenomenological and comorbid features associated in obsessive-compulsive disorder: influence of age of onset. J. Affect. Disord. 79, 241-246.

Olatunji, B.O., Rosenfield, D., Tart, C.D., Cottraux, J., Powers, M.B., Smits, J.A., 2013. Behavioral versus cognitive treatment of obsessive-compulsive disorder: an examination of outcome and mediators of change. J. Consult. Clin. Psychol. 81 (3), 415-428.

Pinto, A., Mancebo, M.C., Eisen, J.L., Pagano, M.E., Rasmussen, S.A., 2006. The Brown Longitudinal Obsessive-Compulsive Study: Clinical features and symptoms of the sample at intake. J. Clin. Psychiatry 67 (5), 703-711.

Quarantini, L.C., Torres, A.R., Sampaio, A.S., Fossaluza, V., de Mathis, M.A., Conceicao do Rosario, M., Fontenelle, L.F., Ferrao, Y.A., Volpato Cordioli, A., Petribu, K., Hounie, A.G., Miguel, E.C., Shavitt, R.G., Koenen, K.C., 2011. Comorbid major depression in obsessive-compulsive disorder patients. Compr. Psychiatry 52, 386-393.

Rector, N.A., Cassin, S.E., Richter, M.A., 2009. Psychological treatment of obsessivecompulsive disorder in patients with major depression: a pilot randomized controlled trial. Can. J. Psychiatry 54 (12), 845-851.

Romanelli, R.J., Wu, F.M., Gamba, R., Mojtabai, R., Segal, J.B., 2014. Behavioral therapy and serotonin reuptake inhibitor pharmacotherapy in the treatment of obsessive-compulsive disorder: a systematic review and meta-analysis of headto-head randomized controlled trials. Depression Anxiety 31, 641-652.

Rosseel, Y., 2012. lavaan: An R package for structural equation modeling. J. Stat. Softw. 48 (2), 1-36.

Ruscio, A.M., Stein, D.J., Chiu, W.T., Kessler, R.C., 2010. The epidemiology of obsessive-compulsive disorder in the national comorbidity survey replication. Mol. Psychiatry 15 (10), 53-63.
Schuurmans, J., van Balkom, A.J.L.M., van Megen, H.J.G.M., Smit, J.H., Eikelenboom, M., Cath, D.C., Kaarsemaker, M., Oosterbaan, D., Hendriks, G.J., Schruers, K.R.J., van der Wee, N.J.A., Glas, G., van Oppen, P., 2012. The Netherlands Obsessive Compulsive Disorder Association (NOCDA) study: design and rationale of a longitudinal naturalistic study of the course of OCD and clinical characteristics of the sample at baseline. Int. J. Methods Psychiatr. Res. 21 (4), 273-285.

Soomro, G.M., Altman, D., Rajagopal, S., Oakley-Browne, M., 2008. Selective serotonin re-uptake inhibitors (SSRIs) versus placebo for obsessive-compulsive disorder (OCD). Cochrane Database Syst. Rev. 23 (1).

Steketee, G., Frost, R., Bogart, K., 1996. The yale-brown obsessive compulsive scale: interview versus self-report. Behav. Res. Ther. 34 (8), 675-684.

Storch, E.A., Wu, M.S., Small, B.J., Crawford, E.A., Lewin, A.B., Horng, B., Murphy, T.K., 2014. Mediators and moderators of functional impairment in adults with obsessive-compulsive disorder. Compr. Psychiatry 55 (3), 489-496.

Subramaniam, M., Abdin, E., Vaingankar, J.A., Chong, S.A., 2012. Obsessive-compulsive disorder: prevalence, correlates, help-seeking and quality of life in a multiracial Asian population. Soc. Psychiatry Psychiatr. Epidemiol. 47, 2035-2043.

Tükel, R., Meteris, H., Koyuncu, A., Tecer, A., Yaziki, O., 2006. The clinical impact of mood disorder comorbidity on obsessive-compulsive disorder. Eur. Arch. Psychiatry Clin. Neurosci. 256, 240-245.

Torres, A.R., Prince, M.J., Bebbington, B.E., Bhugra, D., Brugha, T.S., Farrell, M., Jenkins, R., Lewis, G., Meltzer, H., Singleton, N., 2006. Obsessive-compulsive disorder: prevalence, comorbidity, impact, and help-seeking in the British National Psychiatric Morbidity Survey of 2000. Am. J. Psychiatry 163, 1978-1985. Viswanath, B., Narayanaswamy, J.C., Raijkumar, R.P., Cherian, A.V., Kandavel, T., Math, S.B., Reddy, Y.C.J., 2012. Impact of depression and anxiety disorder comorbidity on the clinical expression of obsessive-compulsive disorder. Compr. Psychiatry 53, 775-782.

Zandberg, L.J., Zang, Y., McLean, C.P., Yeh, R., Blair Simpson, H., Foa, E.B., 2015. Change in obsessive-compulsive symptom mediates subsequent change in depressive symptoms during exposure and response prevention. Behav. Res. Ther. 68, 76-81.

Zitterl, W., Demal, U., Aigner, M., Lenz, G., Urban, C., Zabotoczky, H.G., Zitterl-Eglseer K, K., 2000. Naturalistic course of obsessive-compulsive disorder and comorbid depression. Psychopathology 33, 75-80. 